\author{
ANNA IRENA SZYMAŃSKA \\ Uniwersytet Pedagogiczny w Krakowie, Polska \\ Pedagogical University of Cracow, Poland
}

\title{
Atrakcyjność centrów handlowych jako miejsc dokonywania zakupów i korzystania z oferty usługowej w opinii respondentów
}

\section{Attractiveness of Shopping Malls as the Places of Purchasing and Services Use in the Opinion of Respondents}

\begin{abstract}
Streszczenie: Zasadniczym celem niniejszego artykułu była identyfikacja kluczowych determinant warunkujących określone intencje zachowań konsumentów w zakresie wyboru centrów handlowych jako miejsc korzystania z oferty handlowo-usługowej. Identyfikacja ta oparta była na analizie dostępnej literatury przedmiotu oraz weryfikacji siły oddziaływania wybranych determinant na intencje określonych zachowań konsumentów. W artykule postawiono trzy hipotezy badawcze H1, H2 i H3, a także zaproponowano model teoretyczny, który następnie poddano procesowi weryfikacji z wykorzystaniem modelowania strukturalnego (SEM). Opracowany model poddano również analizie w zakresie poziomu rzetelności oraz dobroci dopasowania. W oparciu o przeprowadzone analizy statystyczne można stwierdzić, że zmodyfikowany model równań strukturalnych nie był satysfakcjonujący i wymaga dalszej uwagi. W toku prowadzonych analiz odrzucono hipotezę H2. Uzyskanie pozytywnej weryfikacji postawionych wstępnie hipotez badawczych H1 i H3 wymaga dalszych badań. W związku z tym nie da się jednoznacznie stwierdzić, że czynniki osobiste oraz lokalizacja w istotny statystycznie sposób wpływają na intencje zachowań konsumentów w zakresie wyboru centrum handlowego jako miejsca korzystania z oferty handlowo-usługowej. W modelowaniu wykorzystano dane pozyskane w ramach badań empirycznych przeprowadzonych na grupie 424 respondentów. Natomiast obliczenia wykonano z wykorzystaniem modułu SEPATH w programie Statistica 13.
\end{abstract}

\footnotetext{
Abstract: The aim of this article was to identify key determinants conditioning specific consumer behaviour intentions during the shopping centres selection. The identification was based on the analysis of available literature on the subject and the verification of strength of impact of selected determinants on the intentions of consumer behaviour. In the article three research hypothesis $\mathrm{H} 1, \mathrm{H} 2, \mathrm{H} 3$ and a conceptual model were proposed. This model was then subjected to the verification process using structural modeling (SEM). The model was also analyzed in terms of the level of reliability and the accuracy of match. On the basis of the statistical analyses it was found that the modified model was not satisfactory and requires further attention. In the course of the analyses, the hypothesis $\mathrm{H} 2$ was rejected. Obtaining positive verification of the hypotheses $\mathrm{H} 1$ and $\mathrm{H} 3$ requires further research. Therefore, it cannot be clearly stated that personal factors and location influence the intentions of consumer behaviour in the selection of a shopping centre as a place to use the commercial and service offer in a statistically significant way. Data used were obtained in empirical studies conducted on the group of 424 respondents. However, the calculations were made using the SEPATH module in the Statistica 13.
} 
Słowa kluczowe: centrum handlowe; modelowanie SEM; zachowania konsumentów

Keywords: consumers behaviours; SEM models; shopping mall

Otrzymano: 2 lutego 2018

Received: 2 February 2018

Zaakceptowano: 22 maja 2018

Accepted: 22 May 2018

\section{Sugerowana cytacja / Suggested citation:}

Szymańska, A.I. (2018). Atrakcyjność centrów handlowych jako miejsc dokonywania zakupów i korzystania z oferty usługowej w opinii respondentów. Prace Komisji Geografii Przemysłu Polskiego Towarzystwa Geograficznego, 32(2), 245-254. https://doi.org/10.24917/20801653.322.17

\section{WSTĘP}

Centra handlowe stanowią istotny element przestrzeni miejskiej i jednocześnie poważną konkurencję dla pozostałych form handlu detalicznego. Proponują one szeroką ofertę produktowo-usługową, akcje promocyjne i degustacyjne, duże własne parkingi i stacje benzynowe, jak również wiele różnych placówek znajdujących się na terenie kompleksu handlowego. Ponadto - w efekcie wielokierunkowego zakresu oddziaływania centrów handlowych (przestrzennego, ekonomicznego, społecznego) - stały się one przedmiotem zainteresowania wielu środowisk naukowych. Należy tu wymienić przede wszystkim nauki techniczne, społeczne, ekonomiczne oraz geografię społeczno-ekonomiczną. Prowadzone badania odnoszą się m.in. do:

- typologii i hierarchizacji centrów handlowych w oparciu o ich wielkość i generację (Sikos, Hoffmann, 2005; Szczyrba, 2005; Lambert, 2006; Kaczmarek, 2010; Mikołajczyk, 2012; Twardzik, 2014),

- postrzegania centrów handlowych jako nowych przestrzeni konsumpcji (Jałowiecki, 2005; Żerebecka, 2005),

- rozpatrywania społecznego oddziaływania centrów handlowych na rozwój miast, funkcji pełnionych w strukturze miasta (Jarczewski, Huculak, 2010; Knecht-Tarczewska, 2011; Hefner, Twardzik, 2013; Rochmińska, 2015; 2016),

- czynników oddziałujących na decyzje konsumentów w zakresie korzystania z oferty centrów handlowych oraz tych świadczących o atrakcyjności centrów handlowych dla konsumentów (Woźniak, 2002; Żalikowski, 2002; Kłosiewicz-Górecka, 2005; Dzieciuchowicz, 2012; Rousseau, Venter, 2014; Płaziak, Szymańska, 2017; Szymańska, Płaziak, 2018),

- identyfikowania profili konsumentów korzystających z oferty handlowo-usługowej centrów handlowych (Chudzik, 2006; Rochmińska, 2011; 2013),

- identyfikowania czynników lokalizacji centrów handlowych i przekształcenia przestrzeni miast na skutek rozszerzania się funkcji handlowej (Kłosowski, 2002; Bogdanov, 2002; Więcław, 2003, Dudek-Mańkowska, Fuhrmann, 2009; Sobala-Gwosdz, Gwosdz, 2011; Celińska-Janowicz, 2011),

- przestrzennego zasięgu oddziaływania centrów handlowych (Chaberko, Ciechowski, Kretowicz, 2013).

Zasadniczym celem niniejszego artykułu była identyfikacja kluczowych determinant wpływających na decyzje konsumentów w zakresie wyboru centrów handlowych jako miejsc zakupów oraz korzystania z oferty usługowej. Identyfikacja ta oparta była 
na analizie dostępnej literatury przedmiotu oraz weryfikacji siły oddziaływania wybranych determinant na intencje określonych zachowań konsumentów. W artykule zaproponowano model teoretyczny, który wstępnie składał się z trzech egzogenicznych oraz jednej endogenicznej zmiennej latentnej oraz 13 opisujących je zmiennych obserwowalnych. Model ten poddano następnie weryfikacji z wykorzystaniem modelowania strukturalnego (SEM).

W modelowaniu wykorzystano dane pozyskane w ramach badań empirycznych przeprowadzonych na grupie 424 respondentów. Natomiast obliczenia wykonano z wykorzystaniem modułu SEPATH w programie Statistica 13.

\section{METODYKA BADAŃ}

W oparciu o przeprowadzoną analizę literatury przedmiotu dokonano identyfikacji kluczowych czynników determinujących wybór centrum handlowego jako miejsca zakupów oraz korzystania z oferty usługowej. Czynniki te następnie zestawiono w trzy grupy, a są nimi: czynniki osobiste, lokalizacja centrum handlowego oraz oferta handlowo-usługowa. Wyszczególnione grupy czynników zostały wybrane jako charakterystyczne i niezależne kategorie, w ramach których postawiono hipotezy badawcze.

Czynniki osobiste, m.in. takie jak odczuwane potrzeby czy preferencje w zakresie sposobu spędzania czasu wolnego, w zasadniczy sposób determinują dokonywane przez konsumentów wybory oraz podejmowane zachowania rynkowe. Podobnie forma i jakość świadczonych usług istotnie oddziaływają na decyzje podejmowane przez konsumentów. Fakt ten stanowił podstawę do sformułowania następującej hipotezy:

H1: Czynniki osobiste, takie jak odczuwane potrzeby, przyjemność spędzania czasu, oczekiwana jakość usług, mają istotny wpływ na wybór centrum handlowego do korzystania z oferty handlowo-usługowej.

Ponadto szeroka, atrakcyjna cenowo oferta handlowo-usługowa oraz sezonowe obniżki cen i promocje przyczyniają się do wyboru centrum handlowego jako miejsca zakupów i spędzania wolnego czasu. Fakt ten stanowił podstawę do sformułowania następującej hipotezy:

H2: Oferta centrum handlowego ma istotny wpływ na wybór centrum handlowego jako miejsca korzystania z oferty handlowo-usługowej.

Istotną determinantą z perspektywy konsumentów wydaje się być również lokalizacja centrum handlowego. Jego dogodne położenie względem miejsca zamieszkania konsumentów oraz innych podmiotów handlowo-usługowych, jak też duża liczba podmiotów gospodarczych funkcjonujących w centrum handlowym mogą decydować o określonych zachowaniach konsumentów. Fakt ten stanowił podstawę do sformułowania następującej hipotezy:

H3: Lokalizacja centrum handlowego ma istotny wpływ na jego wybór do korzystania z oferty handlowo-usługowej. 
W toku dalszych rozważań teoretycznych skonstruowano teoretyczny model badawczy - model równań strukturalnych (SEM), który posłużył następnie do weryfikacji postawionych hipotez H1, H2 i H3. W wyszczególnionym modelu trzem czynnikom, będącym egzogenicznymi zmiennymi latentnymi (czynniki osobiste - CO, oferta handlowo-usługowa centrum handlowego - HU, lokalizacja centrum handlowego - LK), przyporządkowano odpowiednie, charakteryzujące je zmienne jawne (wskaźniki). Również endogeniczna zmienna latentna określona została za pomocą trzech zmiennych jawnych (ryc. 1, tab. 2). Zmienne jawne przedstawione zostały w figurach o kształcie prostokąta, zaś zmienne latentne w elipsach. W modelu SEM założono, że są to zależności reflektywne. Oznacza to, że zmienne jawne stanowią odzwierciedlenie zmiennych ukrytych.

W celu weryfikacji postawionych hipotez badawczych w okresie od października do grudnia 2017 roku przeprowadzono bezpośrednie badania rynkowe z wykorzystaniem kwestionariusza ankiety jako narzędzia badawczego. $\mathrm{W}$ badaniach zastosowano metodę PAPI (Paper \& Pen Personal Interview), tj. bezpośredni wywiad kwestionariuszowy. W badaniach uczestniczyło 424 respondentów - mieszkańców Krakowa. Dobór próby był dogodny, nieprobabilistyczny (nielosowy), a podstawę doboru stanowiła dostępność badanych. Nieco ponad 63\% respondentów uczestniczących w badaniach stanowiły kobiety, a niemal 37\% - mężczyźni. Ponad połowę respondentów (51\%) stanowiły osoby młode w wieku do 30 lat, pracujące zawodowo (ponad 52\%) i mające średnie (47,6\%) lub wyższe (42\%) wykształcenie (tab. 1).

Ryc. 1. Diagram postulowanego modelu równań strukturalnych deklarowanych zachowań respondentów w zakresie wyboru centrum handlowego jako miejsca zakupów i korzystania z oferty usługowej

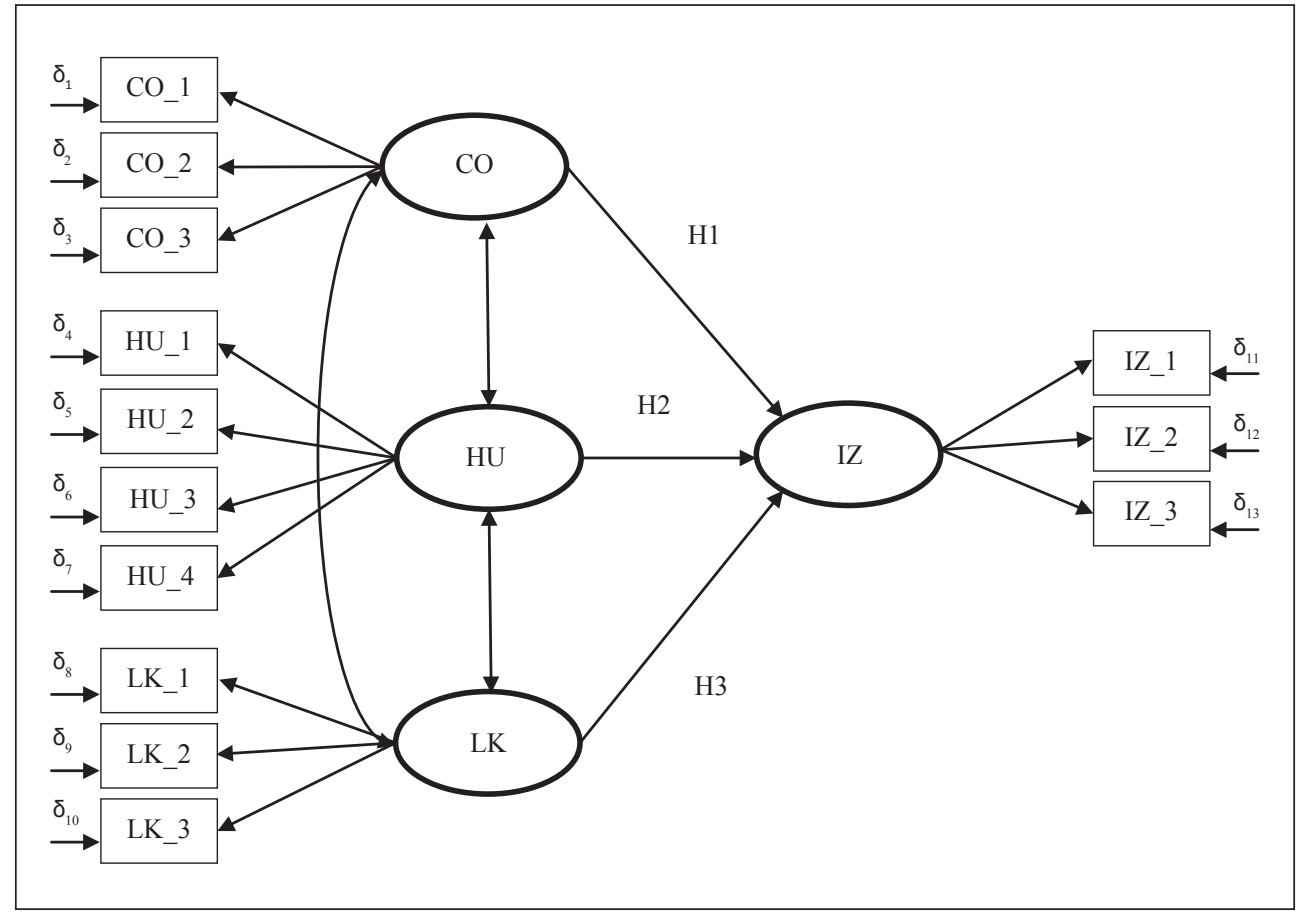

Źródło: opracowanie własne 
Tab. 1. Charakterystyka respondentów uczestniczących w badaniach

\begin{tabular}{|c|c|c|c|}
\hline \multicolumn{2}{|c|}{ Cecha $(\mathrm{N}=424)$} & $\begin{array}{c}\text { Liczba } \\
\text { respondentów }\end{array}$ & $\begin{array}{c}\text { Liczebność } \\
\text { w\% }\end{array}$ \\
\hline \multirow{2}{*}{ Płeć } & kobieta & 269 & 63,4 \\
\hline & mężczyzna & 155 & 36,6 \\
\hline \multirow{4}{*}{ Wiek (w latach) } & $18-20$ & 59 & 13,9 \\
\hline & $21-30$ & 157 & 37,0 \\
\hline & $31-40$ & 104 & 24,5 \\
\hline & 41 i więcej & 104 & 24,5 \\
\hline \multirow{3}{*}{ Wykształcenie } & podstawowe, zawodowe & 44 & 10,4 \\
\hline & średnie & 202 & 47,6 \\
\hline & wyższe & 178 & 42,0 \\
\hline \multirow{3}{*}{ Czym respondent zajmuje się obecnie? } & pracuję & 221 & 52,1 \\
\hline & nie pracuję & 52 & 12,3 \\
\hline & uczę się / studiuję & 151 & 35,6 \\
\hline
\end{tabular}

Źródło: opracowanie własne

Dla czterech zoperacjonalizowanych zmiennych latentnych wyznaczono 13 zmiennych obserwowalnych oraz 13 błędów pomiaru DELTA. Zarówno zmienne latentne, charakteryzujące je zmienne jawne, jak i wartości ładunków czynnikowych oraz błędy pomiaru DELTA wyszczególniono w tab. 2.

Tab. 2. Parametry strukturalne postulowanego modelu równań strukturalnych

\begin{tabular}{|c|c|c|c|}
\hline Konstrukty & Wskaźniki & $\begin{array}{c}\text { Regresja } \\
\text { czynnikowa }\end{array}$ & DELTA \\
\hline \multirow{3}{*}{ CO_Czynniki osobiste } & $\begin{array}{l}\text { CO_1 - Oferta handlowo-usługowa centrum } \\
\text { handlowego w pełni zaspokaja moje potrzeby }\end{array}$ & 0,286 & 0,972 \\
\hline & $\begin{array}{l}\text { CO_2 - Odwiedzając centrum handlowe, kieruję się } \\
\text { przyjemnością spędzonego czasu }\end{array}$ & 0,206 & 1,047 \\
\hline & $\begin{array}{l}\text { CO_3 - Podczas zakupów w hipermarkecie zwracam } \\
\text { uwagę na jakość świadczonych usług }\end{array}$ & 0,189 & 1,062 \\
\hline \multirow{4}{*}{$\begin{array}{l}\text { HU_Oferta handlowo- } \\
\text {-usługowa centrum } \\
\text { handlowego }\end{array}$} & $\begin{array}{l}\text { HU_1 - Przy wyborze sklepu kieruję się cenami, } \\
\text { obniżkami cen i promocjami }\end{array}$ & $-0,123$ & 0,887 \\
\hline & $\begin{array}{l}\text { HU_2 - Odwiedzając centrum handlowe, kieruję się } \\
\text { szerokim wyborem produktów }\end{array}$ & $-0,085$ & 0,385 \\
\hline & $\begin{array}{l}\text { HU_3 - Odwiedzając centrum handlowe, kieruję się } \\
\text { usługami dostępnymi w centrum }\end{array}$ & $-0,056$ & 0,667 \\
\hline & $\begin{array}{l}\text { HU_4 - Podczas zakupów w hipermarkecie odwiedzam } \\
\text { również sklepy znajdujące się w jego pasażu } \\
\text { handlowym }\end{array}$ & $-1,103$ & 0,000 \\
\hline \multirow{3}{*}{ LK_Lokalizacja CH } & $\begin{array}{l}\text { LK_1 - Odwiedzając centrum handlowe, kieruję się } \\
\text { odległością od miejsca zamieszkania }\end{array}$ & 0,037 & 1,780 \\
\hline & $\begin{array}{l}\text { LK_2 - Lokalizacja centrum handlowego może sprzyjać } \\
\text { uzupełnieniu oferty lokalnej sieci placówek handlowo- } \\
\text {-usługowych }\end{array}$ & 0,910 & 0,000 \\
\hline & $\begin{array}{l}\text { LK_3 - Podczas zakupów w hipermarkecie odwiedzam } \\
\text { również sklepy znajdujące się w jego pasażu } \\
\text { handlowym }\end{array}$ & 0,214 & 1,284 \\
\hline
\end{tabular}




\begin{tabular}{|l|l|c|c|}
\hline \multirow{4}{*}{$\begin{array}{l}\text { IŻ_Intencje } \\
\text { zachowania }\end{array}$} & $\begin{array}{l}\text { İ̇_1 - Często korzystam z oferty handlowo-usługowej } \\
\text { centrum handlowego }\end{array}$ & 1,000 & 0,892 \\
\cline { 2 - 4 } & $\begin{array}{l}\text { İ̇_2 - Odwiedzanie hipermarketów jest dla mnie } \\
\text { sposobem na spędzanie wolnego czasu }\end{array}$ & 2,038 & 0,743 \\
\cline { 2 - 4 } & $\begin{array}{l}\text { İ̇_3 - W centrum handlowym spotykam się ze } \\
\text { znajomymi }\end{array}$ & 1,805 & 0,950 \\
\hline
\end{tabular}

M - średnia arytmetyczna, SD - odchylenie standardowe

Źródło: opracowanie własne z wykorzystaniem programu SEPATH, Statistica 13

Parametry modelu są istotne na poziomie $p=0,05$. Wyniki estymacji parametrów modelu hipotetycznego wskazują, że siedem spośród 13 uzyskanych współczynników ścieżkowych (regresja czynnikowa) było istotnych statystycznie i potwierdza dwa spośród trzech postawionych przypuszczeń. Wskaźniki nieopisujące postulowanego modelu to CO2 dla konstruktu „CO_czynniki osobiste”, HU1, HU2, HU3 i HU4 dla konstruktu „HU_oferta handlowo-usługowa CH”, LK1 dla konstruktu „LK_lokalizacja CH”. Z uwagi na niewystarczające dopasowanie postulowanego modelu dokonano jego modyfikacji. Usunięto ścieżki, którym odpowiadały nieistotne statystycznie współczynniki i odpowiadające im wariancje zmiennych objaśniających (ryc. 2). Hipoteza H2, zgodnie z którą oferta centrum handlowego ma istotny wpływ na wybór centrum handlowego jako miejsca korzystania z oferty handlowo-usługowej, okazała się nie być istotna statystycznie i została usunięta z modelu.

Ryc. 2. Diagram zmodyfikowanego modelu równań strukturalnych deklarowanych zachowań respondentów w zakresie wyboru centrum handlowego jako miejsca zakupów i korzystania z oferty usługowej

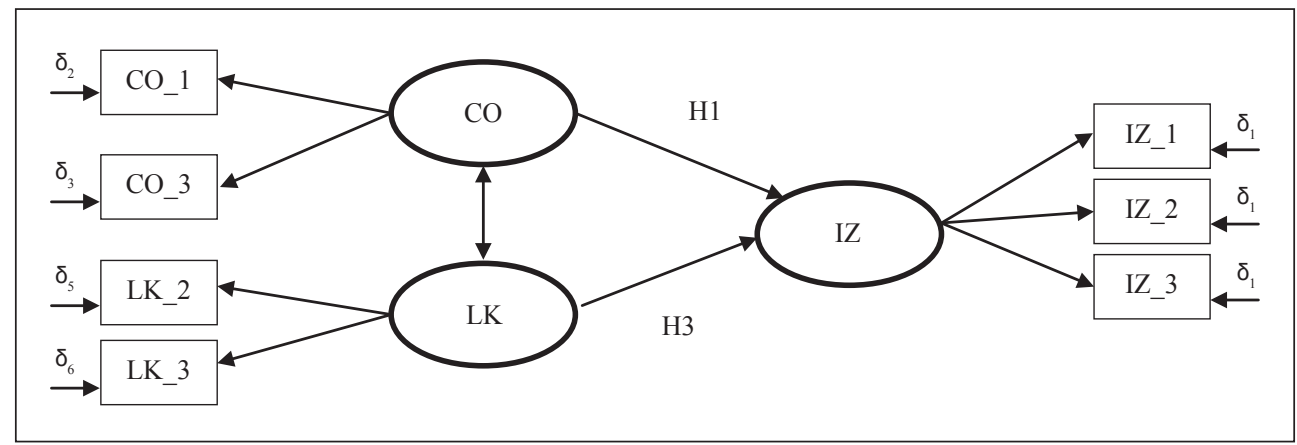

Źródło: opracowanie własne z wykorzystaniem programu Statistica 13

Tab. 3. Miary rzetelności dopasowania zmodyfikowanego modelu równań strukturalnych

\begin{tabular}{|c|c|c|c|c|c|c|}
\hline Konstrukty & Wskaźniki & $\begin{array}{c}\text { Regresja } \\
\text { czynnikowa }\end{array}$ & DELTA & Alfa & RHO & AVE \\
\hline \multirow{2}{*}{$\begin{array}{l}\text { CO_Czynniki } \\
\text { osobiste }\end{array}$} & $\begin{array}{l}\text { CO_1 - Oferta handlowo- } \\
\text {-usługowa centrum } \\
\text { handlowego w pełni zaspokaja } \\
\text { moje potrzeby }\end{array}$ & 0,291 & 0,969 & \multirow{2}{*}{0,172} & \multirow{2}{*}{0,086} & \multirow{2}{*}{0,114} \\
\hline & $\begin{array}{l}\text { CO_3 - Podczas zakupów } \\
\text { w hipermarkecie zwracam } \\
\text { uwagę na jakość świadczonych } \\
\text { usług }\end{array}$ & 0,388 & 0,947 & & & \\
\hline
\end{tabular}




\begin{tabular}{|c|c|c|c|c|c|c|}
\hline \multirow[t]{2}{*}{ LK_Lokalizacja CH } & $\begin{array}{l}\text { LK_2 - Lokalizacja centrum } \\
\text { handlowego może sprzyjać } \\
\text { uzupełnieniu oferty lokalnej } \\
\text { sieci placówek handlowo- } \\
\text {-usługowych }\end{array}$ & 0,910 & 0,000 & \multirow[t]{2}{*}{0,441} & \multirow[t]{2}{*}{0,334} & \multirow[t]{2}{*}{0,346} \\
\hline & $\begin{array}{l}\text { LK_3 - Podczas zakupów } \\
\text { w hipermarkecie odwiedzam } \\
\text { również sklepy znajdujące się } \\
\text { w jego pasażu handlowym }\end{array}$ & 0,214 & 1,284 & & & \\
\hline \multirow{3}{*}{$\begin{array}{l}\text { IŻ_Intencje } \\
\text { zachowania }\end{array}$} & $\begin{array}{l}\text { IŻ_1 - Często korzystam } \\
\text { z oferty handlowo-usługowej } \\
\text { centrum handlowego }\end{array}$ & - & 0,886 & \multirow{3}{*}{0,638} & \multirow{3}{*}{0,864} & \multirow{3}{*}{0,760} \\
\hline & $\begin{array}{l}\text { IŻ_2 - Odwiedzanie } \\
\text { hipermarketów jest dla mnie } \\
\text { sposobem na spędzanie } \\
\text { wolnego czasu }\end{array}$ & 1,967 & 0,783 & & & \\
\hline & $\begin{array}{l}\text { IŻ_3 - W centrum handlowym } \\
\text { spotykam się ze znajomymi }\end{array}$ & 1,811 & 0,926 & & & \\
\hline
\end{tabular}

Źródło: opracowanie własne z wykorzystaniem programu SEPATH, Statistica 13

Statystyki rzetelności AVE, RHO Joreskoga oraz Alfa Cronbacha w przypadku rozważanych egzogenicznych zmiennych ukrytych uzyskały wartość poniżej 0,5 . Wartości analizowanych wskaźników pokazują, że poszczególne zestawy zmiennych obserwowalnych w zasadzie nie mierzą badanego zjawiska i wymagają dalszej uwagi. Natomiast wartość badanych wskaźników dla zmiennej endogenicznej jest powyżej 0,6, co świadczy o dość dobrej rzetelności skali. Można przyjąć, że poszczególne zestawy zmiennych obserwowalnych dla egzogenicznych zmiennych ukrytych wymagają dalszej uwagi, natomiast zmienne jawne opisujące endogeniczną zmienną latentą rzeczywiście mierzą to zjawisko.

Tab. 4. Miary dobroci dopasowania testowanego modelu równań strukturalnych

\begin{tabular}{|l|c|}
\hline \multicolumn{2}{|c|}{ Miary dobroci dopasowania } \\
\hline Chi-kwadrat & 371,813 \\
\hline GFI Joreskoga & 0,954 \\
\hline AGFI Joreskoga & 0,908 \\
\hline Wskaźnik Bentlera-Bonetta & 0,772 \\
\hline RMSEA Steigerna-Linda & 0,083 \\
\hline Wskaźnik Gamma populacji & 0,944 \\
\hline
\end{tabular}

Źródło: opracowanie własne z wykorzystaniem programu SEPATH, Statistica 13

Wskaźniki dopasowania wskazują na względnie akceptowalny poziom dopasowania modelu (tab. 4). Wartość pierwiastka średniokwadratowego błędu aproksymacji $($ RMSEA $=0,08)$ mieści się $\mathrm{w}$ dolnej granicy. Zarówno indeks dobroci dopasowania Gamma, jak i GFI wskazują, że około 0,94\% rzeczywistych kowariancji jest wyjaśnianych przez opracowany model. Nieco niższą wartość przyjęły wskaźniki dobroci dopasowania: AGFI oraz Bentlera-Bonetta. 


\section{PODSUMOWANIE I WNIOSKI KOŃCOWE}

W niniejszym opracowaniu przedstawiono analizę zależności między determinantami: czynnikami osobistymi, ofertą handlowo-usługową centrum handlowego, lokalizacją centrum handlowego, a występowaniem u konsumentów określonych intencji zachowań do odwiedzania centrów handlowych. W analizie wykorzystano modelowanie SEM i utworzono hipotetyczny model SEM, w ramach którego uwzględniono wskaźniki opisujące poszczególne determinanty. Dokonano estymacji i weryfikacji modelu, a następnie jego modyfikacji, wykorzystując w tym celu uzyskane wartości parametrów.

W oparciu o przeprowadzone analizy statystyczne można stwierdzić, że zmodyfikowany model równań strukturalnych nie był satysfakcjonujący i mimo odrzucenia hipotezy H2 (oferta centrum handlowego ma istotny wpływ na wybór centrum handlowego jako miejsca korzystania z oferty handlowo-usługowej) wymaga dalszej uwagi. Uzyskanie pozytywnej weryfikacji postawionych na wstępie hipotez badawczych $\mathrm{H} 1$ i H3 wymaga dalszych badań. Mimo że wskaźniki dobroci dopasowania modelu wskazują na jego względne dopasowanie, to jednak z uwagi na bardzo niskie wartości statystyk rzetelności skali konieczne jest dopracowanie narzędzia wykorzystywanego w badaniach. W związku z tym nie jest możliwe jednoznaczne stwierdzenie, że czynniki osobiste oraz lokalizacja centrum handlowego w istotny statystycznie sposób wpływają na intencje zachowań konsumentów w zakresie wyboru centrum handlowego jako miejsca korzystania z oferty handlowo-usługowej.

\section{Literatura \\ References}

Bogdanov, D. (2002). Problemy lokalizacji wielkopowierzchniowych obiektów handlowych. W: J. Słodczyk (red.). Przemiany bazy ekonomicznej i struktury przestrzennej miast. Opole: Wydawnictwo Uniwersytetu Opolskiego, 383-388.

Celińska-Janowicz, D. (2011). Centra handlowe wobec miejskiej przestrzeni publicznej - nie tylko imitacja. W: I. Jażdżewska (red.). Konwersatorium wiedzy o mieście, XXIV, Człowiek w przestrzeni publicznej miasta. Łódź: Wydawnictwo Uniwersytetu Łódzkiego, 149-156.

Chaberko, T., Ciechowski, M., Kretowicz, P. (2013). Funkcjonowanie wielkiego centrum handlowego w ujęciu przestrzennym i czasowym (na przykładzie Bonarka City Center w Krakowie). Ekonomia. Rynek, gospodarka, społeczeństwo, 32, 121-136.

Chudzik, D. (2006). Wizerunek klienta supermarketów. Handel Wewnętrzny, 4-5, 63-66.

Dudek-Mańkowska, S., Fuhrmann, M. (2009). Centra handlowe trzeciej generacji w Warszawie jako nowe produkty turystyczne. W: A. Stasiak (red.). Kultura i turystyka - wspólnie zyskać. Łódź: Wyższa Szkoła Turystyki i Hotelarstwa, 269-282.

Dzieciuchowicz, J. (2012). Wielkie centrum handlowe $w$ przestrzeni miejskiej i podmiejskiej. Manufaktura w Łodzi i Ptak w Rzgowie. Łódź: Uniwersytet Łódzki.

Hefner, K., Twardzik, M. (2013). Społeczne oddziaływanie nowoczesnych centrów handlowo-usługowych na małe miasta w zewnętrznej strefie aglomeracji śląskiej. Studia Ekonomiczne, 144, 95-108. Katowice.

Jałowiecki, B. (2005). Społeczny język architektury od gotyckiej katedry do hipermarketu. W: W.B. Jałowiecki, A. Majer, M.S. Szczepański, (red.). Przemiany miasta. Wokół socjologii Aleksandra Wallisa. Warszawa: Scholar, 21-36.

Jarczewski, W., Huculak, M. (2010). Wpływ rewitalizacji terenów poprzemysłowych na rynek pracy w woj. śląskim. Problemy Rozwoju Miast, 4, 34-42.

Kaczmarek, T. (2010). Struktura przestrzenna handlu detalicznego: od skali globalnej do lokalnej. Poznań: Bogucki Wydawnictwo Naukowe. 
Kłosiewicz-Górecka, U. (2005). Wielkopowierzchniowe obiekty handlowe jako kluczowy czynnik rozwoju handlu detalicznego w Polsce. Handel Wewnętrzny, 6.

Kłosowski, F. (2002). Hipermarkety w przestrzeni handlowej miast aglomeracji katowickiej. W: J. Słodczyk (red.). Przemiany bazy ekonomicznej i struktury przestrzennej miast. Opole: Wydawnictwo Uniwersytetu Opolskiego, 373-381.

Knecht-Tarczewska, M. (2011). Centrum handlowe jako nowoczesny produkt handlowo-usługowy. Zeszyty Naukowe, 175, 293-303.

Lambert, J. (2006). One Step Closer to a Pan-European Shopping Center Standard. Research Review, 13, 2.

Mikołajczyk, J. (2012). Kreowanie wartości centrum handlowego - perspektywa interesariuszy. Poznań: Wydawnictwo Uniwersytetu Ekonomicznego w Poznaniu.

Płaziak, M., Szymańska, A.I. (2017). Regres czy rozwój lokalnej działalności handlowo-usługowej w najstarszej części Nowej Huty? Przedsiębiorczość-Edukacja, 13, 228-243.

Rochmińska, A. (2011). Zakupy a czas wolny łodzian. Acta Universitatis Lodziensis. Folia Oeconomica, 11.207-217.

Rochmińska, A. (2013). Atrakcyjność łódzkich centrów handlowych oraz zachowania nabywcze i przestrzenne ich klientów. Łódź: Uniwersytet Łódzki.

Rochmińska, A. (2015). Centra handlowe - kreatorzy nowych przestrzeni miejskich. W: A. Wolaniuk (red.). Konwersatorium wiedzy o mieście, XXVIII. Współczesne czynniki i bariery rozwoju miast. Łódź: Uniwersytet Łódzki, 229-246.

Rochmińska, A. (2016). Shopping centres as the subject of Polish geographical research. Geographia Polonica, 89(4), 521-535.

Rousseau, G.G., Venter, D.J.L. (2014). Mall shopping preferences and patronage of mature shoppers. SA Journal of Industrial Psychology/SA Tydskrif vir Bedryfsielkunde, 40(1).

Sikos, T., Hoffmann, M. (2005). Typology of shopping centres in Budapest. Komárno: J. Selye University.

Sobala-Gwosdz, A., Gwosdz, K. (2011). Polska Wschodnia w strategiach lokalizacji sieci hipermarketów. W: M. Woźniak (red.). Uwarunkowania sprawnego działania w przedsiębiorstwie i regionie. Rzeszów: Uniwersytet Rzeszowski, 276-290.

Szczyrba, Z. (2005). Nakupni centra v Ceske Republice - nova forma zabavy a nakupni turistiky. Opole: Politechnika Opolska.

Szymańska, A.I., Płaziak, M. (2018). Consumer Preferences and Behaviours in Shopping Malls in Poland with the particular reference to Krakow. Urban Development Issues Journal, 55, 33-43.

Twardzik, M. (2014). Typologia i znaczenie centrów handlowych dla miast województwa śląskiego. Studia Miejskie, 16.

Więcław, J. (2003). Hipermarkety jako nowy element w strukturze przestrzennej miast Polski na przykładzie Krakowa. W: Z. Gorka, J. Więcław (red.). Badania i podróże naukowe krakowskich geografów. Kraków: Polskie Towarzystwo Geograficzne, 137-146.

Woźniak, G. (2002). Plusy i minusy istnienia sklepów wielkopowierzchniowych w Polsce. W: S. Wrzosek, G. Parzelski, (red.). Za i przeciw super- i hipermarketom. Materiały sympozjum naukowego Wyższej Szkoły Handlowej w Radomiu. Radom, 122-129.

Żalikowski, J. (red.) (2002). Wpływ hipermarketów zachodnich koncernów handlowych na gospodarkę, rynek pracy i dochody władz samorzadowych na przykładzie miasta Białystok $i$ województwa podlaskiego: raport. Białystok: Pro Veritate.

Żerebecka, K. (2005). The space of the shopping centre in Poland. Bulletin of Geography. Socio-economic series, 4, 201-206.

Anna Irena Szymańska, dr, absolwentka studiów z zakresu zarządzania i marketingu Uniwersytetu Ekonomicznego w Krakowie, doktor nauk ekonomicznych w zakresie nauk o zarządzaniu (Katedra Analizy Rynku i Badań Rynkowych - Uniwersytet Ekonomiczny w Krakowie). Adiunkt w Zakładzie Przedsiębiorczości i Gospodarki Przestrzennej Uniwersytetu Pedagogicznego w Krakowie. Zainteresowania badawcze oscylują wokół problematyki potrzeb, preferencji i zachowań rynkowych konsumentów, konsumpcji kolaboratywnej i innych form alternatywnego dostępu do dóbr, nowych trendów w konsumpcji oraz ich implikacji dla strategii biznesowych przedsiębiorstw, jak również zagadnień z obszaru przedsiębiorczości i innowacyjności przedsiębiorstw ze szczególnym uwzględnieniem sektora MŚP oraz gospodarki cyrkularnej. 
Anna Irena Szymańska, Ph.D., she has graduated from Cracow University of Economics, holds an M.Sc. degree in Management and Marketing, and a Ph.D. degree in economic sciences in the field of management sciences (Department of Market Analysis and Marketing Research - Cracow University of Economics). Assistant professor in the Department of Entrepreneurship and Spatial Management at the Pedagogical University of Cracow. Her research interests are related to the issue of consumer needs, preferences and market behaviour, as well as issues in the area of entrepreneurship and innovation with particular emphasis on the SME sector.

\section{Adres/address:}

Uniwersytet Pedagogiczny w Krakowie Zakład Przedsiębiorczości i Gospodarki Przestrzennej ul. Podchorążych St. 2, 30-084 Kraków, Polska

e-mail: aszym@up.krakow.pl 